\title{
Long Coronary Lesions: Challenging Cases for Percutaneous Coronary Intervention
}

\author{
Julio Núñez*, Gema Miñana, Juan Sanchis \\ Department of Cardiology, Hospital Clínico Universitario, Valencia, Spain \\ Email: "yulnunez@gmail.com
}

Received 7 December 2015; accepted 26 January 2016; published 29 January 2016

Copyright $\odot 2016$ by authors and Scientific Research Publishing Inc.

This work is licensed under the Creative Commons Attribution International License (CC BY). http://creativecommons.org/licenses/by/4.0/

(c) (i) Open Access

\begin{abstract}
Long coronary lesions are associated with adverse outcomes after percutaneous coronary intervention since the era of plain balloon angioplasty. Long lesion and long stent length are considered as important predictors of restenosis after percutaneous coronary intervention. With the advent of newer generation drug eluting stents, there has been dramatic reduction in the rates of restenosis and repeat revascularization, even in complex cohort of patients with long coronary lesions. We report one such case of long coronary lesion which was intervened successfully with newer generation, thin strut, biodegradable polymer coated sirolimus-eluting stents.
\end{abstract}

\section{Keywords}

Drug Eluting Stents, Biodegradable Polymer, Percutaneous Coronary Intervention, Treatment Outcome

\section{Introduction}

The treatment of long and diffuse coronary lesions remains a challenge for interventional cardiologists, since the era of balloon angioplasty. A higher angiographic restenosis rate of $58 \%$ has been reported after the intervention of long lesions with balloon angioplasty [1]. Although, the advent of bare metal stents (BMS) was a breakthrough discovery, it was not completely successful in the treatment of advanced coronary artery disease, involving long lesions. Even in the BMS era, implantation of multiple and long stents resulted in higher incidence of diffuse in-stent restenosis [2]. The treatment of resultant diffused in-stent restenosis is again problematic requiring multiple additional PCI's or coronary artery bypass grafting (CABG) [3]. Thus, owing to the challenges and complications involved it became imperative to develop an optimal strategy for percutaneous intervention of long coronary lesions and other complex subsets.

"Corresponding author.

How to cite this paper: Núñez, J., Miñana, G. and Sanchis, J. (2016) Long Coronary Lesions: Challenging Cases for Percutaneous Coronary Intervention. International Journal of Clinical Medicine, 7, 89-93.

http://dx.doi.org/10.4236/ijcm.2016.71008 
The introduction of drug eluting stents (DES) enkindled new hopes and paved the path for long term optimum management of long coronary lesion. Initial experience with first DES, Cypher sirolimus-eluting stents demonstrated that despite the reduction of clinical events, deployment of multiple overlapping stents for long lesion, an approach colloquially called as "full-metal jacket", is an approach with some risks [4]. But at the same time, few randomized trials and registries that involve implantation of DES for long lesions proved that it was associated with reduced rates of restenosis and target lesion revascularization, as compared to BMS [5] [6]. With the passage of time, continuous modification in stent design, architecture and material has helped us develop newer iterations of DES, which are equally effective in long coronary lesions. Technical advances in development of new stents such as thin strut, biodegradable polymer coated sirolimus-eluting stents have encouraged manufacturers to fabricate long stent platforms with the aim to increase the success of percutaneous revascularization avoiding multiple overlapping stents.

We report one such case of long coronary lesion which was intervened successfully with a long newer generation, thin strut, biodegradable polymer coated sirolimus-eluting stents.

\section{Case Report}

A 71-year-old woman was admitted in our centre for an episode of acute chest discomfort that occurred 1 week before. She had type 2 diabetes mellitus and a family history of ischemic heart disease. An electrocardiogram was performed, which showed "rS" pattern in V1-V3 leads and negative T waves in precordial leads. High sensitivity troponin $\mathrm{T}$ was within the normal values in two serial measurements. An abnormal echocardiogram by two-dimensional echocardiography revealed non-dilated left ventricle with normal ejection fraction and anterior and anteroseptal mid-apical hypokinesia. A cardiac magnetic resonance with dipyridamole was performed showing necrosis of three segments in the territory of left anterior descending (LAD) artery with severe peri-infarction ischemia and myocardial viability in most segments. Coronary angiography was performed after 48 hours of admission which showed a single-vessel disease with a focal severe stenosis in the proximal segment and large, subocclusive stenosis in the mid-distal segment of LAD (Figure 1). An angioplasty was performed using a sheathless $6.5 \mathrm{Fr}$ guiding catheter and a hydrophilic soft guide. After predilatation with two semi-compliant $1.5 \times 20 \mathrm{~mm}$ and $2.5 \times 30 \mathrm{~mm}$ balloons (Figure 2), two sirolimus eluting overlapping stents were implanted (Aima Plus $3.0 \times 48 \mathrm{~mm}$ and Aima Plus $3.5 \times 22 \mathrm{~mm}$ distal and proximal, respectively) (Figure 3). Overlapping was limited to $3 \mathrm{~mm}$ and located at the proximal zone. At the end of the procedure an optimal anatomical result and distal TIMI 3 flow was achieved (Figure 4). At 6-month follow-up the patient is asymptomatic and no adverse events have been registered.

\section{Discussion}

Coronary stents are customarily used during angioplasty to improve immediate and long term outcomes and overcome loopholes associated with balloon angioplasty. In the infancy stage of its development, coronary stents had several limitations. The then available metallic platforms fabricated stents had stiffer configuration and shorter lengths of 15 to $20 \mathrm{~mm}$. Multiple overlapping stents were used to treat diffuse long narrowings and specially designed wires were needed to navigate the stent and overcome vessel tortuosity.

Approximately, long lesions consist of $20 \%$ of all percutaneous coronary angioplasty and long or multiple overlapping stents are continuously being used for its treatment [7]. Implantation of multiple stents is timeconsuming and expensive. Moreover, accurate placement of multiple stents is difficult with long overlapping stent segments. Overlapping stents are potential source of neointimal hyperplasia due to physical double layer of stent struts, and inadvertently sometimes a short gap is lapsed out between multiple stents, which increases the risk of acute or sub acute stent thrombosis and restenosis [8].

Pooled analysis of five clinical trials using sirolimus-eluting stents and bare metal stents suggest that overlapping stents increases the risk of late lumen loss and restenosis in both BMS and SES [9]. Contrastingly, a study by Lee et al. comparing the outcomes after overlapping versus one long stent in long coronary lesions demonstrated that overlapping can be used with outcome similar to that of one long stent in long coronary lesions [10]. But at the same time it also stated that age ( $\geq 65$ years old) was an independent risk factor of in-stent restenosis (ISR) (54\% vs. $23 \%$; OR = 4.4; $\mathrm{P}=0.04)$.

This was a case of a long severe disease of LAD. In most of the cases, such types of lesions are referred to surgery because traditional PCI is not successful. And still, if PCI is performed three or four stents are necessary 


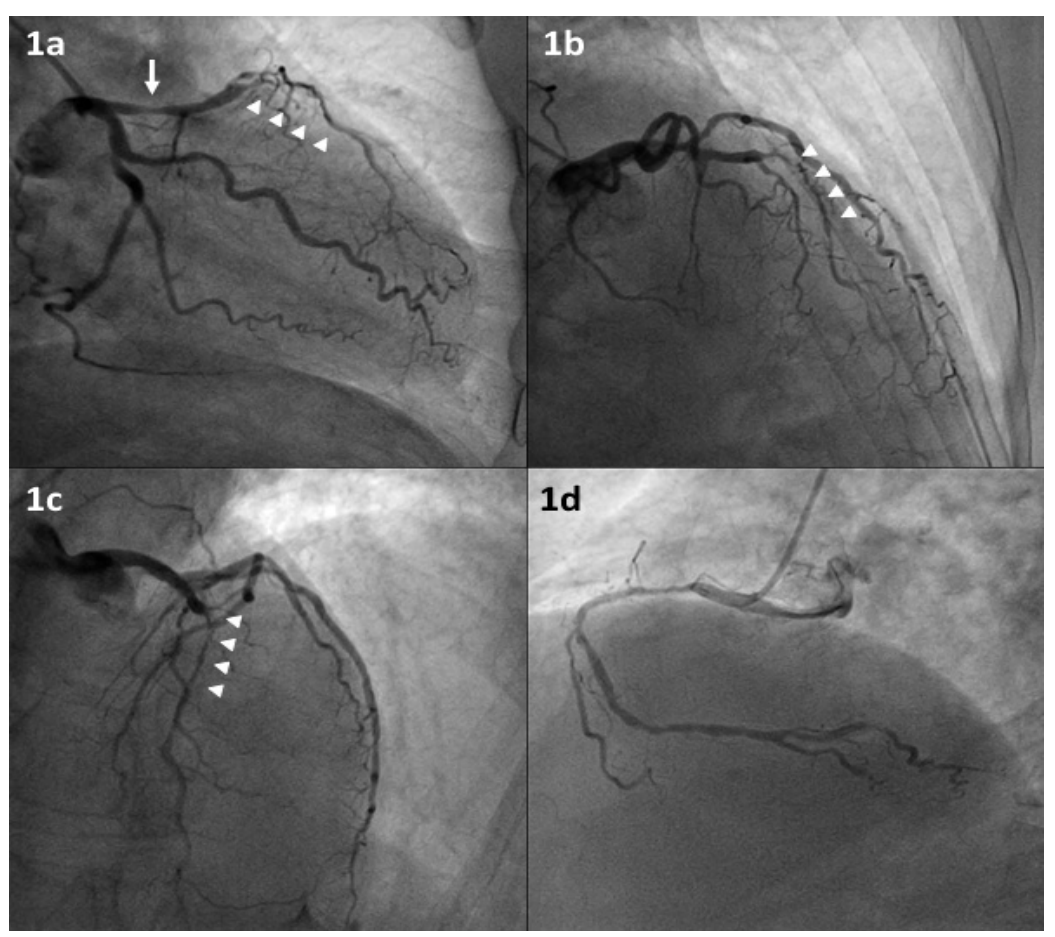

Figure 1. Diagnostic coronary angiography. (a) Left coronary artery, right caudal (spider) projection; (b) Left coronary artery, right cranial projection; (c) Left coronary artery, left cranial projection; (d) Right coronary artery. Severe proximal stenosis (long arrow) and subocclusive mid and distal large stenosis (arrowheads) in left anterior descending artery ((a), (b) and (c)). Diffuse disease in right coronary artery (d).

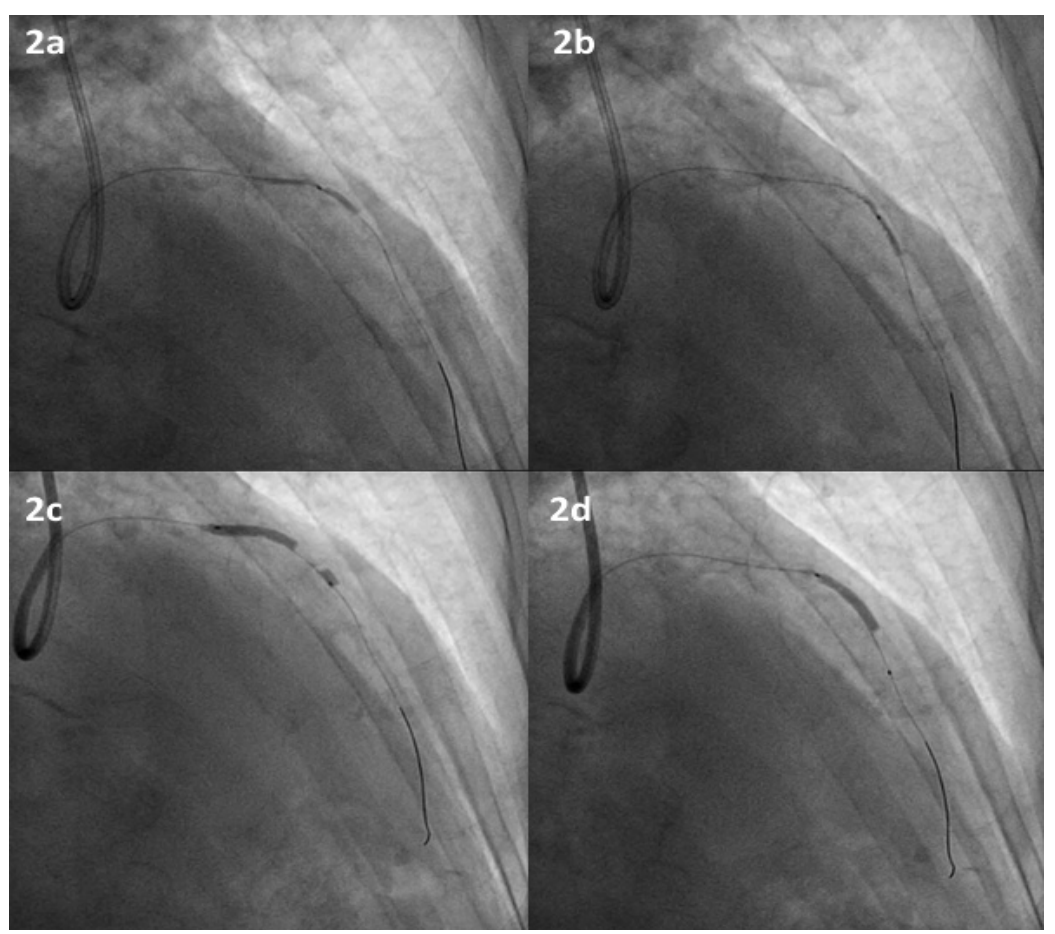

Figure 2. Right cranial projection. Predilatation with $1.5 \times 20 \mathrm{~mm}$. (a) \& (b) and $2.5 \times 30 \mathrm{~mm}$ (c) \& (d) semi-compliant balloons. 


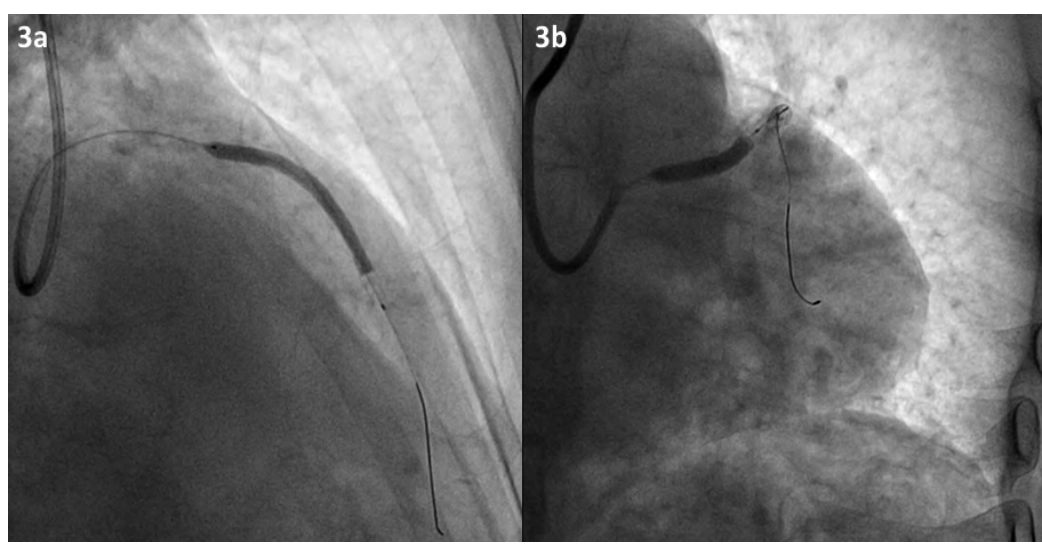

Figure 3. Right cranial projection. Implantation two drug-eluting overlapping stents: AimaPlus $3.0 \times 48 \mathrm{~mm}$ distally (a) and Aima Plus $3.5 \times 22 \mathrm{~mm}$ proximally from ostium (b).

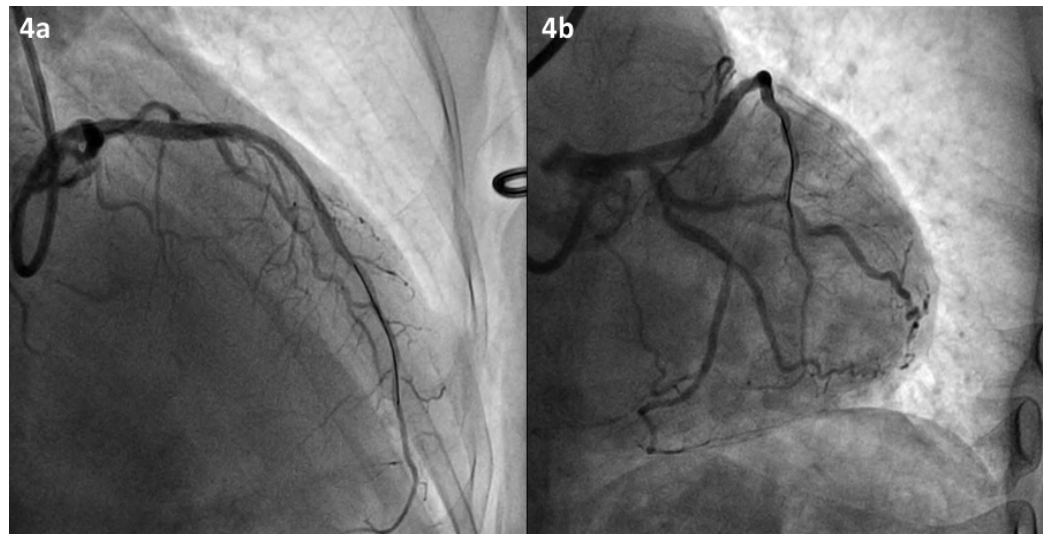

Figure 4. Final result. (a) Right cranial projection; (b) Right caudal (spider) projection.

with high degree of overlapping amongst the stents and this strategy is associated with higher rates of restenosis. Moreover, the patient was elder in age (71 years), which increases the chances of ISR with multiple overlapping stents. Thus the discretion of interventionists to use long stents to minimize the risk of restenosis and adverse outcomes is commendable.

The critical issue in use of long coronary stents is easy navigation and successful deployment to achieve optimal immediate and long-term outcomes. The newer generation biodegradable polymer coated drug eluting stents with thin struts are easy to navigate and deploy. The AIMA plus is one such newer generation biodegradable polymer coated sirolimus-eluting stents that incorporates technical specifications that improve navigability and procedural success. The uniquely designed feature of the AIMA plus is highly flexible S-link to improve four "ability" related aspects; those are deliverability, trackability, pushability, and crossability.

Thus, the newer iterations of DES, with advanced stent design and architecture, can successfully be used for intervention, even in complex cohort of patients with long coronary lesions.

\section{Conclusion}

Despite of the challenges and complications involved in the percutaneous coronary intervention of long coronary lesions, they can be intervened successfully with newer generation drug eluting stents.

\section{Acknowledgements}

None. 


\section{Conflict of Interest}

The authors declare that there is no conflict of interest regarding the publication of this paper.

\section{References}

[1] Serruys, P.W., Foley, D.P., Suttorp, M.-J., Rensing, B.J., Suryapranata, H., Materne, P., et al. (2002) A Randomized Comparison of the Value of Additional Stenting after Optimal Balloon Angioplasty for Long Coronary Lesions: Final Results of the Additional Value of NIR Stents for Treatment of Long Coronary Lesions (ADVANCE) Study. Journal of the American College of Cardiology, 39, 393-399. http://dx.doi.org/10.1016/S0735-1097(01)01760-0

[2] Triantafyllou, K. (2013) Spot Stenting Is Preferable in Long Diffuse Coronary Lesions: Possible Incremental Value of Physiologic and Intracoronary Imaging Modalities. Hospital Chronicles, 8, 71-77.

[3] Bauters, C., Banos, J.-L., Van Belle, E., McFadden, E.P., Lablanche, J.-M. and Bertrand, M.E. (1998) Six-Month Angiographic Outcome after Successful Repeat Percutaneous Intervention for In-Stent Restenosis. Circulation, 97, 318321. http://dx.doi.org/10.1161/01.CIR.97.4.318

[4] Orlic, D., Stankovic, G., Corvaja, N., Airoldi, F., Montorfano, M., Tavano, D., et al. (2004) 1044-53 Full Metal Jacket in the Drug-Eluting Stent Era: In-Hospital and 30-Day Outcome. Journal of the American College of Cardiology, 43, A45-A.

[5] Aoki, J., Ong, A.T., Granillo, G.A.R., McFadden, E.P., van Mieghem, C.A., Valgimigli, M., et al. (2005) Full Metal Jacket (Stented Length $\geq 64 \mathrm{~mm}$ ) Using Drug-Eluting Stents for de Novo Coronary Artery Lesions. American Heart Journal, 150, 994-999. http://dx.doi.org/10.1016/j.ahj.2005.01.050

[6] Kim, Y.H., Park, S.W., Lee, C.W., Hong, M.K., Gwon, H.C., Jang, Y., et al. (2006) Comparison of Sirolimus-Eluting Stent, Paclitaxel-Eluting Stent, and Bare Metal Stent in the Treatment of Long Coronary Lesions. Catheterization and Cardiovascular Interventions, 67, 181-187. http://dx.doi.org/10.1002/ccd.20586

[7] Bourassa, M.G., Lespérance, J., Eastwood, C., Schwartz, L., Cöté, G., Kazim, F., et al. (1991) Clinical, Physiologic, Anatomic and Procedural Factors Predictive of Restenosis after Percutaneous Transluminal Coronary Angioplasty. Journal of the American College of Cardiology, 18, 368-376. http://dx.doi.org/10.1016/0735-1097(91)90588-Z

[8] Menown, I.B. (2013) Very Long Stent Technology: Clinical and Practical Value. Future Cardiology, 9, 641. http://dx.doi.org/10.2217/fca.13.50

[9] Kereiakes, D.J., Wang, H., Popma, J.J., Kuntz, R.E., Donohoe, D.J., Schofer, J., et al. (2006) Periprocedural and Late Consequences of Overlapping Cypher Sirolimus-Eluting Stents: Pooled Analysis of Five Clinical Trials. Journal of the American College of Cardiology, 48, 21-31. http://dx.doi.org/10.1016/j.jacc.2006.02.058

[10] Lee, S.H., Jang, Y., Oh, S.J., Park, K.J., Moon, Y.S., Min, J.W., et al. (2004) Overlapping vs. One Long Stenting in Long Coronary Lesions. Catheterization and Cardiovascular Interventions, 62, 298-302. http://dx.doi.org/10.1002/ccd.20091 